This is the author's final, peer-reviewed manuscript as accepted for publication. The publisher-formatted version may be available through the publisher's web site or your institution's library.

\title{
Lessons learned from professional development workshops on using GIS to teach geography and history in the K-12 classroom
}

Lisa K. Tabor, John A. Harrington, Jr.

\section{How to cite this manuscript}

If you make reference to this version of the manuscript, use the following information:

Tabor, L. K., \& Harrington, J. A., Jr. (2014). Lessons learned from professional development workshops on using GIS to teach geography and history in the K-12 classroom. Retrieved from http://krex.ksu.edu

\section{Published Version Information}

Citation: Tabor, L. K., \& Harrington, J. A., Jr. (2014). Lessons learned from professional development workshops on using GIS to teach geography and history in the K-12 classroom. Geography Teacher, 11(2), 47-54.

Copyright: Copyright @ 2014 National Council for Geographic Education

Digital Object Identifier (DOI): doi:10.1080/19338341.2014.898212

Publisher's Link:

http://www.tandfonline.com/doi/abs/10.1080/19338341.2014.898212\#.VDfiBcVdVQw

This item was retrieved from the K-State Research Exchange (K-REx), the institutional repository of Kansas State University. K-REx is available at http://krex.ksu.edu 


\title{
Lessons Learned from Professional Development Workshops on Using GIS
}

\section{to Teach Geography and History in the K-12 Classroom}

\author{
Lisa K. Tabor \\ Kansas State University, Dept. of Curriculum and Instruction \\ John A. Harrington, Jr. \\ Kansas State University, Dept. of Geography
}

\begin{abstract}
A GIS oriented professional development activity engaged social studies teachers with the importance of maps and graphics in teaching geography and history. With an introduction to ArcGIS Online and National Geographic Map Maker, the activity provided teachers with the ability to make their own maps and identify GIS materials for their classrooms. Conducting the workshop reinforced our belief in the need for considerable hands-on activity with participants allowed to work at their own pace. Pre- and post-event surveys showed positive gains regarding the teachers' likelihood to include GIS based maps and graphics in teaching. The activity provided teachers with enough knowledge of GIS that they were ready to use the technology immediately.
\end{abstract}

Keywords: GIS, geography education, history, professional development

\section{Introduction}

In recent decades, great concern has been expressed over the decline of geographic literacy and less time for geography in the classroom. With these issues in mind, geography education can be reinforced through non-traditional measures. In Kansas, about half the social studies time is devoted to history with the remaining time split among government, economics, and geography. Given this principal role of history in the K-12 social studies curriculum, the use of dual-encoding to integrate geography and history lessons is one approach to bring more geography into the classroom. Considerable scholarship documents the value and approaches to teaching geography and history together. Dual-encoding involves the cognitive psychology theory that verbal and non-verbal information are processed differently and travel along distinct 
pathways in the human mind to create separate representations for information processed in each pathway (Sadoski and Paivio 2004). The verbal and non-verbal codes for representing information are used to organize external information into knowledge that can be utilized, kept, and retrieved for future use (Sadoski and Paivio 2004). The brain perceives, recognizes, interprets, comprehends, appreciates, and remembers experiences that are both text and non-text or verbal and nonverbal. Dual-encoding is a proven method of teaching that increases student learning retention and incorporates multiple learning styles; students learn both subjects better when more than one pathway of learning and memory is being stimulated and with the use of dual-encoding an increase in learning is achieved (Paivio 2006). Due to structural limitations on available classroom time, the more content and knowledge that can be efficiently incorporated into one social studies lesson the better.

Using GIS in the classroom "helps students think critically, use authentic data, and connects them to their own community” (Baker et al. 2012, 255). According to McClurg and Buss (2007), there are fundamental reasons for the incorporation and use of geographic information systems (GIS) in the K-12 classroom. These reasons include that local applications of GIS enable students to complete in-depth studies of local issues and conditions, GIS is especially powerful for analyzing conditions and changes in the environment and looking for solutions, and the use of technology and the meaningful nature of the issues addressed enhance student interest. Furthermore, the growing use of Google Maps on smartphones and the internet provides a realworld example of the power of maps and GIS for students. Geography and history naturally couple together and reinforce the use of dual-encoding and teaching with maps, through subject integration and teaching to multiple discipline standards in one lesson (Tabor \& Harrington 2011). 
With an introduction to classroom use of GIS, teachers and their students will gain greater knowledge of geography, students will learn better and retain more, all while meeting or exceeding new technology standards in the classroom. With this rationale in mind, we applied for funding and received the 2012 National Council for the Social Studies Grant for the Enhancement of Geographic Literacy. Our NCSS funding and partnership with the Kansas Geographic Alliance (KGA) allowed us to complete two workshops. The first was held at Kansas State University in September of 2013 and the second was during the Kansas Social Studies Conference in November of 2013. This paper provides details on the approach that was used in the workshops and participant responses.

\section{Professional Development Workshop Methods}

Binko and Neubert (1984) showed that a well-planned, hands-on, professional development (PD) workshop, where the teacher participant can connect to the material, produces an improvement in the teacher's content and pedagogical methods knowledge. It has been determined that PD workshops provide teachers with increasingly efficient tools for teaching and create enthusiasm for further learning (Ormrod and Cole 1996). Given the history emphasis of the vast majority of social studies teachers, a PD workshop is essential to getting more geography in the mindset of current teachers and into the classroom.

The two PD workshops were similar in format, content, recruitment, and evaluation; they varied as the situation and opportunities differed (Table 1). Both workshops were held on a weekend, with the first workshop lasting six hours and the second workshop lasting three hours. Workshop one was held in the GIS Teaching Lab at Kansas State University in Manhattan, Kansas. Workshop two was held in a high school classroom during the Kansas Social Studies 
Conference in Derby, Kansas. The content was the same for each workshop, but given the differences in length, the participants in the first workshop had significantly more time to explore and practice using each mapping resource discussed in the workshop. Additionally, in workshop one, a GIS professional spoke about GIS from their perspective. Recruitment for workshop one was through the use of existing education email listservs available to the authors and workshop two was offered as an optional workshop during the Kansas Social Studies Conference. Both PD workshops were evaluated using the same pre- and post-surveys.

The overarching goal of the PD workshops was twofold: 1) to provide the participants with background knowledge and rationale for using GIS in the classroom and 2) for the teachers to find or make a resource to be implemented in the classroom immediately. The workshop content was centered on four main topics that progressively built upon each other (Figure 1). The first was teaching with GIS. This consisted of an introduction to GIS and dual-encoding along with the why and how for K-12 classroom use. Examples of teaching with maps focused on teaching geography and history standards together. The next topic was on GIS resources available to Kansas K-12 teachers and examined Esri Story Maps, ArcGIS Online, and National Geographic Map Maker. Since integrating GIS in the classroom involves a technology learning curve, we introduced the teachers to the GeoMentor Program from Esri and National Geographic, provided information on the State of Kansas and Esri K-12 site license agreement, and made sure the teachers knew that the Kansas Geographic Alliance was available for consultation. The third component of the workshop allowed participants to make a web map using ArcGIS Online and National Geographic Map Maker Interactive. A good portion of the time during the workshop was allocated for teachers to become familiar with the online map resources. They were challenged to identify or make at least one resource that could be readily 
implemented into the classroom. The final portion of the workshop was a discussion period where teachers were asked to share what they would use in their classroom and how it would benefit their class.

\section{Data and Results}

The total number of participants for both workshops was 17 people. The pre-survey has an $\mathrm{N}=17$ and due to two participants having to leave the first professional development workshop early, the post-survey $\mathrm{N}=15$. The same pre- and post-survey was used in both workshops and the responses are provided in Tables 2 and 3. At the end of the post-survey, participants were asked to provide feedback on the workshop through an open-ended response question and selected responses are listed following the tables.

All open-ended responses were positive, select answers include:

- "I always joke at my NPS site that I'm not the science-y type. GIS was a "science-y" term I avoided. Now that I know what it is, watch out!"

- "I can do this! My students are about to get mapped!"

- "I'd like to see an advanced session as a follow-up, perhaps bringing in GIS users from a variety of fields to work side-by-side with educators."

- "Give more ideas for implementation of GAW materials. Plus, additional tool for $3^{\text {rd }}$ graders. GIS is not such a mystery."

- "After the tutorial online however you gave us a wonderful intro and the confidence to explore. Well done!”

The pre- and post-survey responses showed that a mixture of grade level teachers participated in the workshops and that the majority had no prior GIS-related training. The workshop prepared participants to use dual-encoding and integrate subjects and standards as they teach. Participants responded that they are now more likely to include a map or graphic as they 
teach. Following the workshop, most participants rated themselves as now aware of Esri and National Geographic resources available for them to use. All participants responded that the workshop equipped them with basic knowledge of online GIS that they could use in the classroom and the majority of participants reported now feeling comfortable using GIS in their classrooms. The open-ended responses supported the rationale for doing this research, helped document the teacher enthusiasm for what they had learned, and corroborated the gain in knowledge that can be seen from the pre- to post-workshop survey.

\section{Lessons Learned}

Successes. We identified that teachers want to learn about how to use GIS in their classrooms and knowledge of programs and training sessions to support implementation are important. The opportunity provided to network with a GIS professional was very helpful for the teachers in better understanding GIS and its applications to society. Connecting geography to history attracts social studies teachers and history-based examples are essential. Finally, there are numerous great GIS resources available for teachers online.

Challenges. As with all technologies, there were minor technological difficulties in each workshop experience and participants had to overcome some technology-induced frustration while learning a new skill. It is important to have a number of workshop leaders to assist participants as they make their way into the online GIS resources, Finding geography and history standards that aligned to create a good classroom example was a challenge and called for additional time to be spent in creation of these materials. Kansas geography and history are taught at the $7^{\text {th }}$ grade level, so we selected examples from those grade level standards. A follow 
up workshop might encourage teachers at varying grade level to create examples that will work for them. In recruiting participants it was problematic to get people to willingly give up their own time on a weekend for professional development.

The survey results and interactions with the workshop participants helped us recognize several successes and challenges regarding using GIS to teach geography and history together. It is hoped that these lessons learned will serve as advice for those interested in offering similar professional development, as well help guide us in the our next steps for this research and workshop series.

\section{Next Steps}

There are several research directions we are pursuing. Teachers are interested in and willing to use GIS in their classroom and it has been demonstrated that the one-day workshop can make an impact. Now longitudinal data is needed on how the teachers went on to implement the information and materials they gained; we are currently working on acquiring this type of data through follow-up surveys with the teachers who participated in these workshops. We are set up to continue this professional development workshop series in our state. We have made connections with local teacher professional development service centers and will continue to offer these workshops as part of our state geographic alliance programmatic activity. We are also investigating offering a university-based Teaching with GIS course to reach pre-service undergraduate teachers and in-service teachers who are continuing their education.

\section{Acknowledgements}


We would like to thank the National Council for the Social Studies and Herff Jones Nystrom for support through the 2012 grant for the Enhancement of Geographic Literacy, the Esri Education Team, the Kansas Geographic Alliance, and Dr. Shawn Hutchinson.

\section{References}

Baker, T.R., J.J. Kerski, N.T. Huynh, K. Viehrig, and S.W. Bednarz. 2012. Call for an agenda and center for GIS education research. Review of International Geographical Education Online 2(3), 254-288.

Binko, J.B. and G.A. Neubert. 1984. An inservice education model: Teachers and professors as equals. Journal of Teacher Education 35(6): 15-17.

McClurg, P.A. and A. Buss. 2007. Professional development: Teachers use of GIS to enhance student learning. Journal of Geography 106: 79-87.

Ormrod, J.E. and D.B. Cole. 1996. Teaching content knowledge and pedagogical content knowledge: A model from geographic education. Journal of Teacher Education 47(1): 37-42.

Paivio, A. 2006. Dual coding theory and education. The University of Michigan School of Education Conference: 1-19.

Sadoski, M. \& A. Paivio. 2004. A dual coding theoretical model of reading. In Theoretical Models and Processes of Reading, ed. R.B Ruddell and N.J. Unrau, 5th ed., 1329-1362. Newark, DE: International Reading Association.

Tabor, L. \& J. Harrington. 2011. Using geography to help teach history: Dual-encoding history lesson plans. Research in Geographic Education 13(1): 20-34. 